\section{Effect of Fluoride and Simplified Adhesive Systems on the Bond Strength of Primary Molars and Incisors}

Leily Macedo Firoozmand 1 , Lawanne Ellen Carvalho Noleto², Isabella Azevedo

Gomes $^{2}$, José Roberto de Oliveira Bauer ${ }^{1}$, Meire Coelho Ferreira ${ }^{2}$
'Dentistry Department 1,

UFMA - Universidade Federal do

Maranhão, São Luís, MA, Brazil

${ }^{2}$ Dentistry Department,

UNICEUMA - Universidade

Ceuma, São Luís, MA, Brazil

Correspondence: Dra. Meire Coelho Ferreira, Rua Josué Montello, $\mathrm{n}^{\circ}$

1, Renascença 11, 65.075-120 São

Luís, MA, Brasil. Tel: + 55-98-

3214-4273/98895-5888. e-mail:

meirecofe@hotmail.com
The aim of this study was evaluate in vitro the influence of simplified adhesive systems (etch-and-rinse and self-etching) and $1.23 \%$ acidulated phosphate fluoride (APF) on the microshear bond strength ( $\mu$-SBS) of composite resins on primary molars and incisors. Forty primary molars and forty incisors vestibular enamel was treated with either the self-etching Clearfil SE Bond (CSE, Kuraray) or etch-and-rinse Adper Single Bond 2 (SB2, $3 \mathrm{M} / \mathrm{ESPE}$ ) adhesive system. Each group was subdivided based on the prior treatment of the enamel with or without the topical application of 1.23\% APF. Thereafter, matrices were positioned and filled with composite resin and light cured. After storage in distilled water at $37 \pm 1^{\circ} \mathrm{C}$ for $24 \mathrm{~h}$, the specimens were submitted to $\mu$-SBS in a universal testing machine. Kruskal-Wallis and Mann-Whitney tests $(p<0.05)$ showed that the prior application of $1.23 \%$ APF led to a significant reduction in bond strength. The type of adhesive exerted no significant influence bond strength. In the inter-group analysis, however, significantly bond strength reduction was found for the incisors when CSE was employed with APF. Adhesive failure was the most common type of fracture. The bond strength was affected by the prior application of $1.23 \%$ APF and type of tooth.
Key Words: fluoride, microshear bond strength, enamel, primary teeth.

\section{Introduction}

Restorations with a composite resin are widely performed in pediatric dentistry. It is therefore important to evaluate the effectiveness of novel materials and techniques on primary teeth to select products with the best longevity, thereby avoiding the repetition of restorative procedures.

The adhesion of restoration materials to teeth is closely related to the type of bonding system employed (1). A selfetching system does not require the prior application of phosphoric acid. The primer and adhesive may be in separate botlles or together in a single bottle. Studies indicate that similar bond strength on both the dentin and enamel is achieved with a self-etching system or a conventional adhesive system that involves previous etching (2). Thus, the use of a simplified adhesive system is preferable in pediatric dentistry due to the lower number of steps involved, which reduces the time the patient spends in the chair.

Enamel on primary teeth has a non-prismatic surface layer (3), which seems to be more resistant to dissolution by acid than the prismatic layer (4) and hinders the adhesion of resin materials. The use of fluoride for the prevention of caries is another important factor to consider. Considering the different types of fluoride, the ADA clinical guideline recommended for individuals at risk of dental caries and aged from 5 years old, 2.26\% fluoride varnish or 1.23\% acidulated phosphate fluoride (APF) gel. As the frequency of topical applications of fluoride in high concentration, it should be based on risk indicators and degree of caries activity present in the patient (5). Acidulated phosphate fluoride (APF) at a concentration of $1.23 \%$ is commonly employed for the effective treatment of carious lesions in the early stage (6). The $\mathrm{pH}$ of $1.23 \% \mathrm{APF}$ is 3.2 to 3.5 and the low concentration of hydrogen dissolves the enamel surface to form calcium fluoride $\left(\mathrm{CaF}_{2}\right)(7)$. APF application in pediatric dentistry should be performed taking into account other treatments at the same clinic session. The application of fluoride solutions prior to restorative treatment can affect the adhesive strength of the material. In a study involving bovine enamel, the prior application of a fluoride varnish and $1.23 \%$ APF led to a reduction in the bond strength of resin materials (8). APF is also reported to diminish surface roughness on the enamel of both primary and permanent teeth $(9,10)$, which can affect the adhesion of composite resins.

The aim of the present in vitro study was to evaluate the influence of simplified adhesive systems (etch-and-rinse and self-etching) and $1.23 \%$ APF on the bond strength of composite resins on primary molars and incisors. The following hypotheses were tested: 1) no significant difference is found between the adhesive systems employed; 2) fluoride does not affect bond strength and 3) the type of tooth (molar or incisor) exerts no influence on the quality of the bond. 


\section{Material and Methods}

\section{Tooth Selection and Preparation}

This study received approval from the Human Research Ethics Committee of Ceuma University, Brazil (process \#00680/10). Calculation of sample size to compare mean adhesive strength was previously performed. It was considered a 95\% confidence level, a 6.4 standard deviation (11) with a minimum difference to be detected between the groups of $6 \mathrm{MPa}$. A minimum of 9 samples was determined for each group. Considering possible losses during preparation of samples, 10 specimens per group was used.

Forty exfoliated primary molars and 40 exfoliated primary incisors were obtained from patients under treatment at the University's Pediatric Dentistry and Orthodontics Clinic. The teeth were embedded in chemically activated acrylic resin (Jet, Clássico, São Paulo, SP, Brazil) with the vestibular face exposed. To maintain the nonprismatic layer of the enamel intact, the teeth were not submitted to sanding. Prophylaxis was performed with the aid of a Robson brush and non-fluoridated extra-fine pumice stone paste for $10 \mathrm{~s}$. Table 1 displays the bonding systems employed, composition of the products and application method.

Each group of teeth (molars and incisors) was randomly divided into two groups: self-etching Clearfil SE Bond (CSE; Kuraray Medical Inc., Okayama, Sakazu, Japan) and etch-and-rinse Adper Single Bond 2 (SB2; 3M/ESPE, St. Paul, MN, USA), which were randomly subdivided into an experimental group (1-min application of topical 1.23\% APF (DFL, Jacarepaguá, RJ, Brazil) and control group (no pretreatment of enamel).

\section{Bonding Procedures}

Three cylindrical matrices (Tygon tubing, TYG-030, Saint-Gobain Performance Plastic, Maime Lakes, FL, USA) were positioned on the vestibular surface of each tooth and filled with a composite resin (Filtek Z250; 3M/ESPE) with the aid of a calcium hydroxide applicator (SSWhite/ Duflex, Rio de Janeiro, RJ, Brazil). All light curing procedures were performed using the curing light device (Optilux 501; Demetron/Kerr, Danbury, CT, USA) with light intensity of 600 $\mathrm{mW} / \mathrm{cm}^{2}$. The bonding systems were photopolymerizated as reported in Table 1, and $40 \mathrm{~s}$ was used for composite resins.

After storage in distilled water at $37 \pm 1^{\circ} \mathrm{C}$ for $24 \mathrm{~h}$, the matrices were removed to expose the cylinders of composite resin adhered to the enamel surface.

\section{Microshear Bond Strength Testing}

For the microshear test, a stainless steel wire (Morelli, São Paulo, SP, Brazil) with a diameter of $0.2 \mathrm{~mm}$ was positioned around each cylinder of composite resin and aligned with the adhesive-tooth interface. The specimens were placed in a universal testing machine (EMIC; DL 2000, São José dos Pinhais, PR, Brazil) operating at 0.5 $\mathrm{mm} / \mathrm{min}$ until the occurrence of fracture. The mean value of the three composite resin fractures was used for the analysis.

\section{Fracture Analysis}

The surface of the specimens was then examined under a stereomicroscope (Kozo Optical and Electronical Instrumental, Nanjing, Jiangsu, China) at 10× magnification for the determination of the type of fracture at the

Table 2. Type of fractures following microshear test

\begin{tabular}{lc}
\hline Score & Type of fracture \\
\hline 1 & $\begin{array}{c}\text { Adhesive fracture (composite resin/ } \\
\text { adhesive/enamel interface) }\end{array}$ \\
2 & Cohesive fracture in enamel \\
3 & Cohesive fracture in composite resin \\
4 & Mixed fracture (composite resin/adhesive/enamel) \\
\hline
\end{tabular}

Table 1. Materials, composition and application method

\begin{tabular}{|c|c|c|}
\hline Bonding system & Composition & Application method \\
\hline Clearfil SE Bond (CSE) & $\begin{array}{c}\text { Primer: MDP, HEMA, camphorquinone hydrophilic } \\
\text { dimethacrylate, N.N-diethanol p-toluidine, water. } \\
\text { Bonder: MDP, Bis-GMA, HEMA, camphorquinone } \\
\text { hydrophilic dimethacrylate, N.N-diethanol } \\
\text { p-toluidine, silanized colloidal silica. }\end{array}$ & $\begin{array}{l}\text { - Cleaning of tooth } \\
\text { - Drying of tooth; active application of primer for } \\
20 \text { s; quick drying with compressed air }(2 \mathrm{~s}) \\
\text { - Application of bond, quick drying }(2 \mathrm{~s}), \\
\text { followed by light activation for } 20 \mathrm{~s}\end{array}$ \\
\hline Single Bond 2 (SB2) & $\begin{array}{l}\text { Dimethacrylates, Bis-GMA, HEMA, copolymer } \\
\text { of polyacrylic and polyitaconic acids, photo- } \\
\text { initiator, ethanol, water, 5-nm charged particles. }\end{array}$ & $\begin{array}{c}\text { - Cleaning of tooth } \\
\text { - Application of phosphoric acid (30 s) } \\
\text { - Abundant rinsing for } 30 \mathrm{~s} / \text { drying for } 10 \mathrm{~s} \text {; } \\
\text { - Active application for } 20 \mathrm{~s} \text { and application of } 2 \text { layers } \\
\text { - Rapid drying to evaporate solvent } \\
\text { - Light activation for } 20 \mathrm{~s}\end{array}$ \\
\hline
\end{tabular}


adhesive-tooth interface. Table 2 displays the scoring system used for the different types of fractures.

\section{Statistical Analysis}

The data were submitted to Levene's test for the analysis of equality of variance and the Shapiro-Wilk test for the determination of normal or non-normal distribution. As the data demonstrated non-normal distribution, the Kruskal-Wallis and Mann-Whitney tests with the Bonferroni correction $(p<0.008)$ were used for the dependent variables "bond strength (in MPa)" and "type of fracture". Spearman's correlation coefficients were calculated to determine correlations between bond strength and type of fracture. The PASW Statistics (v.17; SPSS Inc., Chicago, IL, USA) was used for the statistical analysis.

\section{Results}

\section{Microshear Bond Strength}

Table 3 displays the bond strength in the different groups. In the group of molars, statistically significant differences were found between CSE-F and CSE-C as well as SB2-F and SB2-C ( $p=0.000$ and $p=0.011$, respectively). In the group of incisors, statistically significant differences were also found between CSE-F and CSE-C as well as SB2-F and SB2-C ( $p=0.000$ and $p=0.000$, respectively). In the inter-group analysis, significantly less bond strength was found for the incisors in comparison to the molars when CSE was employed without fluoride $(p=0.007)$.

\section{Fracture Analysis}

Table 4 displays the absolute and relative frequencies of the type of fractures in the molar and incisor groups, the most frequent of which was adhesive fracture.

A weak negative correlation was found between bond strength (MPa) and type of fracture $(r=-0.12 ; p=0.31)$.

\section{Discussion}

The study of techniques and materials that make procedures simpler and more efficacious is of considerable importance in pediatric dentistry. In the present investigation, no significant difference in bond strength was found between the two adhesive systems analyzed. However, the prior application of $1.23 \%$ APF influenced bond strength on primary molars and incisors using both the self-etching and conventional adhesive systems. Moreover, lower bond strength was found on the incisors in comparison to the molars with the selfetching system was employed. Thus, the findings demonstrate that the null hypothesis was rejected with regard to both APF and type of tooth.

The microshear test, which was used in the present investigation, is considered adequate for the measure of the strength of adhesive restorations (12), as "macro" tests have a greater frequency of cohesive enamel fractures and lower frequency of adhesive failures (13). Studies involving microshear and microtensile tests indicate that the former yields more adequate results when evaluating the bond strength 
achieved in different adhesive systems (14), with a greater number of adhesive failures (16).

The simplified etch-and-rinse SB2 adhesive system contains charged nanoparticles, which make the adhesive layer stronger and more durable. However, the filler does not exert an influence on degree of conversion or water sorption pattern (17). The presence of chains of polyalkenoic acid is one of the factors that may contribute to the satisfactory bond strength, as such chains spread through the enamel, dislocating calcium and phosphate ions of the apatite crystals (16). The self-etching CSE system has 10-MDP molecules that unit to form a stable bond with the Ca-MDP salt. This system involves the formation of a nano-layer of adhesive, making the adhesive interface more resistant to biodegradation, which favors the clinical longevity of the bond produced by 10-MDP-based adhesives (17).

The prior application of $1.23 \%$ APF resulted in a statistically significant reduction in bond strength independently of the adhesive system, which is in agreement with data described in the literature (18). Among the different types of high concentration fluoride compounds, it is observed in the literature (8), that the 1.23\% APF gel and 5\% sodium fluoride varnish promote reduction in the bond strength values when compared to untreated and teeth treated with 2\% neutral fluoride gel. Previous studies suggest that maximum adhesion of composite resins to dental enamel is achieved when acid etching is performed two weeks after the application of $\operatorname{APF}(9,10)$. Based on the mechanism of action of fluoride, a high concentration of fluoridated compounds form a greater amount of $\mathrm{CaF}_{2}$, which is more stable in the oral environment than generally assumed (19) and may interfere with bonding longevity.

To the best of our knowledge, no previous studies have compared primary molars and incisors with regard to the bond strength of restorations achieved with etchand-rinse and self-etching systems. Thus, an analysis was performed in the present investigation to determine the influence of the type of tooth on bond strength. Studies on the eruption chronology of primary and permanent teeth allow the establishment of the mean duration of primary teeth in the oral cavity, which is 8.5 years for molars and 6.8 years for incisors $(20,21)$. This factor may explain the lower bond strength found on the incisors in comparison to the molars when the self-etching system was employed. It is suggested that the non-prismatic layer of the enamel may be more thicker when the primary tooth has been in the oral cavity for a shorter length of time, which could exert a negative impact on the bond, since this layer is more resistant to dissolution by acids (22), which could offers inappropriate conditions for resin infiltration and tag formation (23). However, further studies are needed to either confirm or refute this hypothesis.

Analyzing the adhesive interface, a large number of the failures occurred between the enamel and resin, which is in agreement with data reported in the literature (24). According to Braga et al. (13) and El Zohairy et al. (14), a larger number of failures in microtests are adhesive fractures, which ensures more accurate results. In the present study no association between failure mode and the values of shear bond strength was observed, corroborating to Ramires-Romito et al. (25).

Accordingly, no significant differences were found between the etch-and-rinse and self-etching adhesive systems, whereas bond strength was influenced by the prior application of 1.23\% APF and the type of tooth on which the restorations were performed. This study found that the type of teeth can influence the adhesion of resinous materials. Prior topical application of fluoride in enamel reduces the adhesion of resin materials to this substrate.

\section{Resumo}

0 objetivo deste estudo foi avaliar a influência dos sistemas adesivos simplificados (condicionamento ácido total e auto-condicionante) e fluorfosfato acidulado a 1,23\% (FFA) na resistência de união ao microcisalhamento ( $\mu$-RUC) de resinas compostas em molares e incisivos decíduos. 0 esmalte vestibular de quarenta molares e quarenta incisivos deciduos foi tratado com Clearfil SE Bond (CSE, Kuraray) ou Adper Single Bond 2 (SB2, 3M/ESPE). Cada grupo foi subdividido com base no tratamento prévio do esmalte com ou sem aplicação tópica de FFA a 1,23\%. Em seguida, matrizes foram posicionadas e preenchidas com resina composta e posterior fotopolimerização. Depois da armazenagem em água destilada a $37 \pm 1{ }^{\circ} \mathrm{C}$ por $24 \mathrm{~h}$, os espécimes foram submetidos ao $\mu$-RUC em uma máquina de ensaio universal. Teste Kruskal-Wallis e Mann-Whitney $(p<0,05)$ mostraram que a aplicação prévia de FFA a $1,23 \%$ levou a uma redução significativa na resistência de união. 0 tipo de adesivo não exerceu influência significativa na resistência de união. $\mathrm{Na}$ análise intergrupos, entretanto, redução significativa na resistência de união foi encontrada para os incisivos quando CSE foi empregado sem FFA. Falha adesiva foi o tipo de fratura mais comum. A resistência de união foi afetada pela aplicação de FFA a 1,23\% e tipo de dente.

\section{Acknowledgements}

This study was supported by the following Brazilian fostering agencies: Coordination of Higher Education (CAPES) of the Ministry of Education and the State of Maranhão Research and Scientific/Technological Assistance Foundation (FAPEMA).

\section{References}

1. Cehreli ZC, Kecik D, Kocadereli I. Effect of self-etching primer and adhesive formations on shear bond strength of orthodontic brackets. Am J Orthod Dentofacial Orthop 2005;127:573-579.

2. Marquezan $M$, da Silveira BL, Burnett LH Jr, Rodrigues CR, Kramer PF. Microtensile bond strength of contemporary adhesives to primary enamel and dentin. J Clin Pediatr Dent 2008;32:127-132.

3. Sabel N. Enamel of primary teeth-morphological and chemical aspects. Swed Dent J 2012;222:1-77.

4. Shimada Y, Tagami J. Effects of regional enamel and prism orientation on resin bonding. Oper Dent 2003;28:20-27.

5. Maguire A. ADA clinical recommendations on topical fluoride for caries 
prevention. Evid Based Dent. 2014;15:38-39.

6. Murakami C, Bönecker M, Corrêa MS, Mendes FM, Rodrigues CR. Effect of fluoride varnish and gel on dental erosion in primary and permanent teeth. Arch Oral Biol 2009;54:997-1001.

7. Rošin-Grget $K$, Peroš K, Sutej I, Bašić $K$. The cariostatic mechanisms of fluoride. Acta Med Acad 2013;42:179-188.

8. Leódido $\mathrm{G}$ da R, Fernandes $\mathrm{HO}$, Tonetto MR, Presoto $C D$, Bandéca MC, Firoozmand LM. Effect of fluoride solutions on the shear bond strength of orthodontic brackets. Braz Dent J 2012;23:698-702.

9. Choi S, Cheong Y, Lee GJ, Park HK. Effect of fluoride pretreatment on primary and permanent tooth surfaces by acid-etching. Scanning 2010;32:375-382.

10. Choi S, Rhee Y, Park JH, Lee GJ, Kim KS, Park JH, et al.. Effects of fluoride treatment on phosphoric acid-etching in primary teeth: an AFM observation. Micron 2010;41:498-506.

11. Tedesco TK, Garcia EJ, Soares FZ, Rocha R de 0, Grande RH. Effect of two microshear test devices on bond strength and fracture pattern in primary teeth. Braz Dent J 2013;24:605-609.

12. Andrade AM, Moura SK, Reis A, Loguercio AD, Garcia EJ, Grande RH. Evaluating resin-enamel bonds by microshear and microtensile bond strength tests: effects of composite resin. J Appl Oral Sci 2010;18:591598.

13. Braga RR, Meira JB, Boaro LC, Xavier TA. Adhesion to tooth structure: a critical review of "macro" test methods. Dent Mater 2010;26:38-49.

14. El Zohairy AA, Saber MH, Abdalla Al, Feilzer AJ. Efficacy of microtensile versus microshear bond testing for evaluation of bond strength of dental adhesive systems to enamel. Dent Mater 2010;26:848-854.

15. Martins GC, Meier MM, Loguercio AD, Reis A, Gomes JC, Gomes OM. Effects of adding barium-borosilicate glass to a simplified etch-andrinse adhesive on radiopacity and selected properties. J Adhes Dent 2014;16:107-114.
16. Tanumiharja M, Burrow MF, Tyas MJ. Microtensile bond strengths of glass ionomer (polyalkenoate) cements to dentine using four conditioners. J Dent 2000;28:361-366.

17. Yoshida $Y$, Yoshihara $K$, Nagaoka N, Hayakawa $S$, Torii $Y$, Ogawa T, et al.. Self-assembled nano-layering at the adhesive interface. J Dent Res 2012;91:376-381.

18. Meng $\mathrm{CL}$, $\mathrm{Li} \mathrm{CH}$, Wang WN. Bond strength with APF applied after acid etching. Am J Orthod Dentofacial Orthop 1998;114:510-513.

19. Ogaard B, Rolla G, Helgeland K. Uptake and retention of alkali soluble and insoluble fluoride in sound enamel in vivo after mouthrinses with 0.05\% or 0.2\% NaF. Caries Res 1983;17:520-524.

20. Yan AA, Cisse D, Tamba A, Diop F, Diagne F, Diop K, et al.. Chronology and date of eruption of primary teeth in Senegal. Odontostomatol Trop 2001;24:34-38.

21. Guna SM, Tenny J. Longitudinal study of age and order of eruption of primary teeth in Indian children. J Clin Exp Dent 2010;2:113-116.

22. Daronch $M$, de Goes $M$, Chan D, Grande RHM. Antibacterial and conventional self-etching primer system: morphological evaluation of intact primary enamel. J Clin Pediatric Dent 2003;27:251-256.

23. Hashimoto $M$, Ohno $H_{\text {, Yoshida }}$, Hori M, Sano $H_{\text {, Kaga }}$, et al.. Resinenamel bonds made with self-etching primers on ground enamel. Eur J Oral Sci 2003;111:447-453.

24. Perdigão J, Lopes L, Lambrechts $P$, Leitão J, Van Meerbeek B, Vanherle G. Effect of a self-etching primer on enamel shear bond strengths and SEM morphology. Am J Dent 1997;10:141-146.

25. Ramires-Romito $A C$, Reis $A$, Loguercio AD, Hipólito VD, de Goes MF, Singer JM, et al.. Microtensile bond strength of sealant and adhesive systems applied to occlusal primary enamel. Am J Dent 2007;20:114120. 